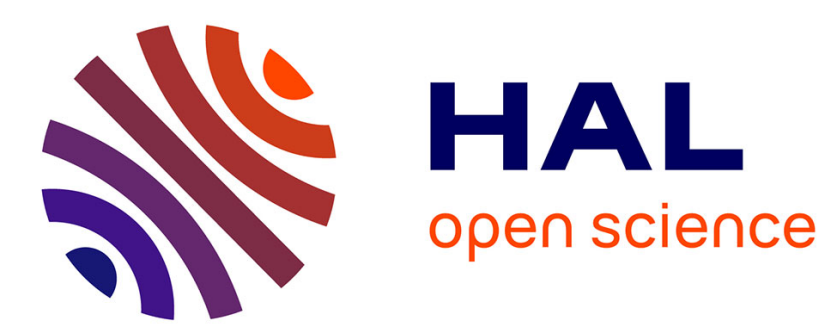

\title{
Stabilisation of Takagi-Sugeno models with maximum convergence rate
}

Mohammed Chadli, Didier Maquin, José Ragot

\section{To cite this version:}

Mohammed Chadli, Didier Maquin, José Ragot. Stabilisation of Takagi-Sugeno models with maximum convergence rate. IEEE International Conference on Fuzzy Systems, FUZZ-IEEE 2004, Jul 2004, Budapest, Hungary. pp.CDROM. hal-00151296

\section{HAL Id: hal-00151296 https://hal.science/hal-00151296}

Submitted on 29 Mar 2014

HAL is a multi-disciplinary open access archive for the deposit and dissemination of scientific research documents, whether they are published or not. The documents may come from teaching and research institutions in France or abroad, or from public or private research centers.
L'archive ouverte pluridisciplinaire $\mathbf{H A L}$, est destinée au dépôt et à la diffusion de documents scientifiques de niveau recherche, publiés ou non, émanant des établissements d'enseignement et de recherche français ou étrangers, des laboratoires publics ou privés. 


\title{
Stabilisation of Takagi-Sugeno Models with Maximum Convergence Rate
}

\author{
Mohammed Chadli, Didier Maquin, José Ragot \\ Centre de Recherche en Automatique de Nancy, CNRS, UMR 7039 \\ 2, Avenue de la forêt de Haye, 54516 Vandœuvre les Nancy - France. \\ Phone: (33) 3835957 02, Fax: (33) 383595644 \\ Email: \{Mohamed.Chadli, Didier.Maquin, José.Ragot\}@ensem.inpl-nancy.fr
}

\begin{abstract}
This paper deals with the stabilization of TakagiSugeno (T-S) models using state feedback controllers. Relaxed sufficient exponential stability conditions are given for both continuous and discrete multiple models. The stability conditions of the closed loop multiple models are expressed in linear matrix inequalities (LMI) form. To optimize the degree of stability, a formulation in term of generalized eigenvalues problem (GEVP) is proposed.
\end{abstract}

\section{INTRODUCTION}

A lot of theoretical researches on the design of T-S model controller has been reported. Using a Common Quadratic Lyapunov Function (CQLF), sufficient conditions for the stability and stabilizability have been established $[3][5][7][11][12][14][15][19]$. These stability conditions may be expressed in linear matrix inequalities (LMI) form [6]. To obtain relaxed stability conditions, nonquadratic Lyapunov functions are used [1][7][10][18][17]. Some results use the properties of M-matrices to study subclass of multiple models which admit a CQLF $[20,13]$ and sufficient conditions in LMI form for global exponential stability are established [2]. LMI constraints have been also used for pole assignment in LMI regions to achieve desired performances of multiple controllers and T-S observers

[8][16]. This approach includes the multiple models [7] and can be also seen also as polytopic linear differential inclusion [6].

This paper is organized as follows. Section 2 recalls the structure of continuous-time and discrete-time T-S models. In section 3, under the assumption that the T-S model is locally controllable, sufficient conditions for the global exponential stability are derived in LMI form for T-S model controller. The designed controller guarantees not only stability but also decay rate constraint. In section 4 , the derived conditions are extended to discrete-time multiple model case. These results are formulated as a Generalized Eigen-Value Problem (GEVP).

The following notation is used: $\lambda_{\min }$ (.) and $\lambda_{\max }($.$) denote$ respectively the minimum and the maximum eigenvalues of (.), $X>0$ denotes a symmetric positive definite matrix, $r$ is the maximum number of submodels simultaneously activated, $\sum_{i<j}^{n}()=.\sum_{i=1}^{n} \sum_{j=1, i<j}^{n}(),. I_{n}=\{1,2, \ldots, n\}$ and

$L_{c}\left(X_{i j}, P\right)=\left(\frac{X_{i j}+X_{j i}}{2}\right)^{T} P+P\left(\frac{X_{i j}+X_{j i}}{2}\right)$
$L_{d}\left(X_{i j}, P\right)=\left(\frac{X_{i j}+X_{j i}}{2}\right)^{T} P\left(\frac{X_{i j}+X_{j i}}{2}\right)-P$

\section{T-S MODEL REPRESENTATION}

A T-S model [4][9], proved to be universal approximator [13][17], is based on the interpolation between several LTI local models as follows:

Continuous time case :

$$
\begin{aligned}
& \dot{x}(t)=\sum_{i=1}^{n} \mu_{i}(z(t))\left(A_{i} x(t)+B_{i} u(t)\right) \\
& y(t)=\sum_{i=1}^{n} \mu_{i}(z(t)) C_{i} x(t)
\end{aligned}
$$

Discrete time case :

$$
\begin{aligned}
& x(k+1)=\sum_{i=1}^{n} \mu_{i}(z(k))\left(A_{i} x(k)+B_{i} u(k)\right) \\
& y(k)=\sum_{i=1}^{n} \mu_{i}(z(k)) C_{i} x(k)
\end{aligned}
$$


where $n$ is the number of submodels. $(u(t), x(t), y(t)) \in \mathbb{R}^{m} \times \mathbb{R}^{p} \times \mathbb{R}^{l}$ are respectively the control input, the state and the output vector, $\left(A_{i}, B_{i}, C_{i}\right) \in \mathbb{R}^{p \cdot p} \times \mathbb{R}^{p \cdot m} \times \mathbb{R}^{l \cdot p} \quad$ describes the $\mathrm{i}^{\text {th }}$ LTI submodel and $z(.) \in \mathbb{R}^{q}$ is the decision variable vector, depending on the measurable state variables and possibly on the input. The normalized activation function $\mu_{i}($.$) in$ relation with the ith submodel is such that:

$$
\left.\sum_{i=1}^{n} \mu_{i}(z)\right)=1, \mu_{i}(z) \geq 0 \quad \forall i \in I_{n}
$$

More details about this type of representation can be found in [7][9].

\section{STABILISATION OF CONTINUOUS T-S MODELS}

The closed loop model of (1) with the control law

$u(t)=-\sum_{i=1}^{n} \mu_{i}(z(t)) K_{i} x(t)$

is as follows

$\dot{x}(t)=\sum_{i=1}^{n} \sum_{j=1}^{n} \mu_{i}(z(t)) \mu_{j}(z(t)) G_{i j} x(t)$

where

$G_{i j}=A_{i}-B_{i} K_{j}$

Assumption 1 : It is assumed that the system (1) is locally controllable, i.e. the pairs $\left(A_{i}, B_{i}\right), \forall i \in I_{n}$ are controllable.

The decay rate, also called degree of stability, in the continuous time case, is defined to be the largest $\alpha \geq 0$ such that

$\lim _{t \rightarrow \infty} e^{\alpha t}\|x(t)\|=0$

holds for all nonzero trajectories $x(t)$ of the system (5). For the controller design, it is supposed that the system (1) is locally controllable.

In order to guaranteeing a certain decay rate, the authors of [19] proposed additional constraints utilizing the dominant terms $\left(G_{i i}=A_{i}-B_{i} K_{i}\right)$ and the coupled terms $\left(G_{i j}=A_{i}-B_{i} K_{j}\right)$. These additive constraints on the level of the coupled terms lead, obviously, to more conservative conditions.
In the following, the decay rate is guaranteed by deferring the problem only on the dominant terms naturally supposed controllable (assumption 1). Thus the idea to maintain the relaxation of the coupled terms is respected.

The following proposition is needed to prove the result of theorem 1.

Proposition 1 : Taking into account the properties of the activation functions (3), the following inequality holds :

$\sum_{i=1}^{n} \mu_{i}^{2}(z) \geq \frac{1}{r}, \quad \forall r \in\{2, . ., n\}$

where $r$ is the maximum number of submodels simultaneously activated.

Proof: From the properties of the activation functions (3)

$1=\left(\sum_{i=1}^{n} \mu_{i}(z)\right)^{2}=\sum_{i=1}^{n} \mu_{i}(z)^{2}+2 \sum_{i<j}^{n} \mu_{i}(z) \mu_{j}(z)$

and the property [3] : $\sum_{i=1}^{n} \mu_{i}(z)^{2} \geq \frac{2}{r-1} \sum_{i<j}^{n} \mu_{i}(z) \mu_{j}(z)$

the result (8) is easily derived.

The following theorem establishes global exponential stability of the model (5) with prescribed degree of stability.

Theorem 1: Suppose that there exist symmetric matrices $P>0$ and $Q \geq 0$, matrices $K_{i}$ and scalar $\alpha>0$ such that $\forall i<j \in I_{n}$ :

$L_{c}\left(G_{i i}, P\right)+(r-1) Q+2 \alpha r P<0$

$L_{c}\left(G_{i j}, P\right)-Q \leq 0$

and $\mu_{i}(z(t)) \mu_{j}(z(t)) \neq 0$. Then the closed-loop multiple model (5) is globally exponentially stable with, at least, a decay rate equal to $\alpha$.

Proof: Taking into account the properties of the activation functions (3), we can write:

$\sum_{i=1}^{n} \mu_{i}(z)^{2}\left(L_{c}\left(G_{i i}, P\right)+(r-1) Q+2 \alpha r P\right)+$

$2 \sum_{i<j}^{n} \mu_{i}(z) \mu_{j}(z)\left(L_{c}\left(G_{i j}, P\right)-Q\right)<0$ 
which gives with the property (9) :

$G(z)^{T} P+P G(z)+\left(r \sum_{i=1}^{n} \mu_{i}(z)^{2}-1\right) Q+2 \alpha r P \sum_{i=1}^{n} \mu_{i}(z)^{2}<0$

where

$G(z)=\sum_{i=1}^{n} \sum_{j=1}^{n} \mu_{i}(z) \mu_{j}(z) G_{i j}$

The proposition 1 allows to write :

$G(z)^{T} P+P G(z)+2 \alpha P<0$

which corresponds to

$\dot{V}(x(t))+2 \alpha V(x(t))<0$

with $V(x(t))=x(t)^{T} P x(t), P>0$. Finally, we obtain:

$\|x(t)\| \leq e^{-\alpha t} \kappa(P)\|x(0)\|$

where $\kappa(P)=\left(\frac{\lambda_{\max }(P)}{\lambda_{\min }(P)}\right)^{1 / 2}$

which constitutes the proof of theorem 1 .

The largest lower bound on the decay rate may be found by solving the following GEVP in $X, Y, N_{i}$ and $\alpha$ :

Maximize $\alpha$

Subject to

$\left\{\begin{array}{l}X>0 \\ X A_{i}^{T}+A_{i} X-N_{i}^{T} B_{i}^{T}-B_{i} N_{i}+(r-1) Y+2 \alpha r X<0 \\ X\left(A_{i}^{T}+A_{j}^{T}\right)+\left(A_{i}+A_{j}\right) X-N_{i}^{T}\left(B_{i}^{T}+B_{j}^{T}\right)- \\ \left(B_{i}+B_{j}\right) N_{i}-2 Y \leq 0\end{array}\right.$

with $Y=X Q X, K_{i}=N_{i} X^{-1}, i \in I_{n}$

The result given in [19] is proved to be less conservative than the one given in [3] when $r=n$, i.e. when the activation functions have global support. In the following we extend the result of [19] to exponential stability with prescribed decay rate.
Theorem 2 : Suppose that there exists symmetric matrices $P>0$ and $Q_{i j}$, matrices $K_{i}$ and scalar $\alpha \geq 0$ such that $\forall i<j \in I_{n}$ :

$L_{c}\left(G_{i i}, P\right)+Q_{i i}+2 \alpha r P<0$

$L_{c}\left(G_{i j}, P\right)+Q_{i j} \leq 0$

$\left(\begin{array}{ccc}Q_{11} & Q_{12} \cdots & Q_{1 n} \\ Q_{12} & \ddots & \vdots \\ \vdots & & \\ Q_{1 n} & \cdots & Q_{n n}\end{array}\right)>0$

and $\mu_{i}(z(t)) \mu_{j}(z(t)) \neq 0$. Then the closed-loop T-S model (5) is globally exponentially stable with at least a decay rate equal to $\alpha$.

Proof: It can be easily established as in theorem1.

It should be noted that in theorem 1 and theorem 2 the relaxation of the coupled terms $\left(G_{i j}\right)$ is maintained which is not the case of that given in [3].

\section{IV.DISCRETE T-S MODEL CASE}

The closed loop model of (2) with the control law $u(k)=-\sum_{i=1}^{n} \mu_{i}(z(k)) K_{i} x(k)$ is :

$x(k+1)=\sum_{i=1}^{n} \sum_{j=1}^{n} \mu_{i}(z(k)) \mu_{j}(z(k)) G_{i j} x(k)$

where $G_{i j}$ is defined in (6).

The decay rate in the discrete time case is defined to be the largest $\beta \geq 1$ such that

$\lim _{k \rightarrow \infty} \beta^{k}\|x(k)\|=0$

holds for all nonzero trajectories $x(k)$ of the system (19). The following theorem establishes sufficient global exponential stability conditions of the system (19) with prescribed degree of stability.

Theorem 3 : Suppose that there exists symmetric matrices $P>0$ and $Q \geq 0$, matrices $K_{i}$ and scalar $0 \leq \alpha<1$ such that $\forall i<j \in I_{n}$ :

$L_{d}\left(G_{i i}, P\right)+(r-1) Q+r(1-\alpha) P<0$

$L_{d}\left(G_{i j}, P\right)-Q \leq 0$ 
and $\mu_{i}(z(t)) \mu_{j}(z(t)) \neq 0$. Then the closed-loop T-S model (19) is globally exponentially stable with at least a decay rate equal $\alpha^{1 / 2}$.

Proof: After multiplying (21a) by $\mu_{i}^{2}(z(t))$ and (21b) by $2 \mu_{i}(z(t)) \mu_{j}(z(t))$ and summation, with the use of proposition 1 , we obtain :

$G(z)^{T} P G(z)-\alpha P<0$

where $G(z)$ is defined in (13), which corresponds to

$V(z(k+1), x(k+1))-\alpha V(z(k), x(k))<0$

with $V(z(k), x(k))=x(k)^{T} P x(k), P>0$. Finally, we obtain:

$\|x(k)\| \leq \alpha^{k / 2} \kappa(P)\|x(0)\|$

where $\kappa(P)$ is defined in (16).

The largest lower bound on the decay rate may be found by solving the following GEVP in $X, Y, N_{i}$ and $\alpha$ :

Minimize $\alpha$

Subject to

$X>0$

$\left(\begin{array}{cc}(1-r(1-\alpha)) X-(r-1) Y & * \\ A_{i} X-B_{i} N_{i} & X\end{array}\right)>0$

$\left(\begin{array}{cc}X+Y & * \\ \frac{1}{2}\left(\left(A_{i}+A_{j}\right) X-B_{i} N_{j}-B_{j} N_{i}\right) & X\end{array}\right) \geq 0$

with $Y=X Q X, K_{i}=N_{i} X^{-1}, i \in I_{n}$. Let us note that $\alpha=1$ corresponds to global asymptotic stability of (19) which is the classic asymptotic stability conditions.

\section{CONCLUSION}

In this paper, the stabilization with prescribed degree of stability is considered for both continuous and discrete T-S model. Using CQLF, sufficient conditions for the global exponential asymptotic stability are derived. The maximization of the decay rate is formulated as a generalized eigenvalues problem. These results could be directly applied to design a T-S observer.

\section{REFERENCES}

[1] M. Chadli, D. Maquin, J. Ragot, "Nonquadratic stability analysis of Takagi-Sugeno models", In Proc. of the 41th IEEE CDC, Las Vegas, Nevada, pp. 2143-2148, 2002.
[2] M. Chadli, D. Maquin, J. Ragot, "On the stability analysis of a class of multiple models ", In Proc. of the 42th IEEE CDC, Hawaii, Dec. 9-12, 2003.

[3] K. Tanaka, T. Ikeda, H. O. Wang, "Fuzzy regulators and fuzzy observers: relaxed stability conditions and LMI-based design", IEEE Trans. on Fuzzy Systems, vol. 6, no. 2, pp. 250-256, 1998.

[4] T. Takagi, M. Sugeno, "Fuzzy identification of systems and its application to modelling and control", IEEE Trans. on Systems, Man, Cybernetics, vol. 15, no.1, pp. 116-132, 1985.

[5] M. Chadli, D. Maquin, J. Ragot, "An LMI formulation for output feedback stabilisation in multiple model approach", In Proc. of the IEEE CDC, Las Vegas, Nevada, pp. 311-316, 2002.

[6] S. Boyd, L. Elghaoui, E. Feron and V. Balakrishnan. Linear matrix inequalities in systems and control theory, Philadelphia, PA: SIAM, 1994.

[7] M. Chadli. Stability and control of systems described by multiple model: an LMI approach. Thesis of Institut National Polytechnique de Lorraine, Nancy, France, 2002.

[8] K. Tanaka, M. Nishimuna, H. O. Wang, "Multi-objective fuzzy control of high rise/high speed elevators using LMI", $A C C$, Philadelphia, Pennsylvanie, pp. 3450-3454, 1998.

[9] M. Sugeno, G. T. Kang, "Structure identification of fuzzy model", Fuzzy Sets and Systems, vol. 28, pp15-33, 1988.

[10] M. Johansson, A. Rantzer, K. Arzén, "Piecewise quadratic stability of fuzzy systems", IEEE Trans. On Fuzzy Systems, vol. 7, no. 6, pp. 713-722, 1999.

[11] G. Feng, S.G. Cao, N. W. Rees, C. M. Cheng, "Analysis and design of model based fuzzy control systems", IEEE Trans. on Systems Man and Cybernetics, vol. 30, no. 1, pp. 204-210, 2000.

[12] M. Chadli, D. Maquin, J. Ragot., "Output stabilisation in multiple model approach", In Proc. of the IEEE Control Conference Application CCA'02, Glasgow, Scotland, pp. 1315-1320, Sep. 2002.

[13] .Y. Mori, T. Mori and Y. Kuroe, "Somme new subclasses of systems having a common quadratic Lyapunov function and comparison of known subclasses". In Proc. of the 40th IEEE CDC, Orlando, Florida, pp. 2179-2180, 2001.

[14] Narendra K. S., Balakrishnan J., " A common Lyapunov function for stable LTI systems with commuting A-matrices ", IEEE Trans. On Automatic Control, vol. 39, no. 12, pp. 2469-2471, 1994.

[15] M. Chadli, D. Maquin, J. Ragot., "Observer-based controller for T-S models", In Proc. of the IEEE International Conference on SMC, Tunisia, Oct. 2002.

[16] C. J. Lopez-Toribio, R. J. Patton, "T-S fuzzy faulttolerant for a nonlinear system", In Proc. of CDC, Phoenix, Arizona, pp. 4368-4373, Dec. 1999.

[17] K. Tanaka, T. Hori, H. O. Wang, "A fuzzy lyapunov approach to fuzzy control system design”, $A C C$, Arlington, VA, pp. 4790-4795, 2001.

[18] K. Tanaka, T. Hori, H. O. Wang, "New parallel distributed compensation using time derivative of membership functions: a fuzzy Lyapunov approach", In Proc. of CDC, Orlando, Florida, pp. 3942-3947, 2001.

[19] E. Kim, H. Lee. "New approaches to relaxed quadratic stability condition of fuzzy control systems" IEEE Trans. on Fuzzy Sets, vol. 8, no. 5, pp. 523-534, 2000.

[20] M. Akar and U. Ozguner, "Decentralized techniques for the analysis and control of T-S fuzzy systems", IEEE. Trans. on Fuzzy Systems, 8, (6), pp. 691-704, 2000. 